\title{
Investigating the molecular control of deer antler extract on articular cartilage
}

\author{
Baojin Yao', Zhenwei Zhou', Mei Zhang ${ }^{2}$, Xiangyang Leng ${ }^{3 *}$ (i) and Daqing Zhao ${ }^{1 *}$
}

\begin{abstract}
Background: Deer antler is considered as a precious traditional Chinese medicinal material and has been widely used to reinforce kidney's yang, nourish essence, and strengthen bone function. The most prominent bioactive components in deer antler are water-soluble proteins that play potential roles in bone formation and repair. The aim of this study was to explore the molecular control and therapeutic targets of deer antler extract (DAE) on articular cartilage.
\end{abstract}

Methods: DAE was prepared as previously described. All rats were randomly divided into Blank group and DAE group (10 rats per group) after 7-day adaptive feeding. The rats in DAE group were orally administrated with DAE at a dose of $0.2 \mathrm{~g} / \mathrm{kg}$ per day for 3 weeks, and the rats in Blank group were fed with drinking water. Total RNA was isolated from the articular cartilage of knee joints. RNA sequencing (RNA-seq) experiment combined with quantitative real-time polymerase chain reaction (qRT-PCR) verification assay was carried out to explore the molecular control and therapeutic targets of DAE on articular cartilage.

Results: We demonstrated that DAE significantly increased the expression levels of functional genes involved in cartilage formation, growth, and repair and decreased the expression levels of susceptibility genes involved in the pathophysiology of osteoarthritis.

Conclusions: DAE might serve as a candidate supplement for maintaining cartilage homeostasis and preventing cartilage degeneration and inflammation. These effects were possibly achieved by accelerating the expression of functional genes involved in chondrocyte commitment, survival, proliferation, and differentiation and suppressing the expression of susceptibility genes involved in the pathophysiology of osteoarthritis. Thus, our findings will contribute towards deepening the knowledge about the molecular control and therapeutic targets of DAE on the treatment of cartilage-related diseases.

Keywords: Deer antler extract, Articular cartilage, RNA sequencing, Molecular mechanism, Therapeutic targets

\section{Background}

Deer antler is considered as a precious traditional Chinese medicinal material and has been widely used to reinforce kidney's yang, nourish essence, and strengthen bone function [1]. The most prominent bioactive components in

\footnotetext{
*Correspondence: leng_xiangyang@163.com; zhaodaqing1963@163.com

${ }^{3}$ The Affiliated Hospital of Changchun University of Chinese Medicine, Changchun 130117, China

'Jilin Ginseng Academy, Changchun University of Chinese Medicine, Changchun 130117, China

Full list of author information is available at the end of the article
}

deer antler are water-soluble proteins that play potential roles in bone formation and repair [2-6]. However, little is known regarding their effects on cartilage development and growth. Deer antler is a fantastic mammalian appendage with characteristics of rapid growth and annually regeneration [7-9]. The longitudinal growth of the antler was considered as a modified endochondral ossification process that is analogous to the long bone growth originated from mesenchymal condensation, chondrocytic differentiation, and ossification [10]. During rapid growth stage, deer antler is capable to grow as rapidly as $2 \mathrm{~cm}$ per

(c) The Author(s). 2021 Open Access This article is licensed under a Creative Commons Attribution 4.0 International License, which permits use, sharing, adaptation, distribution and reproduction in any medium or format, as long as you give appropriate credit to the original author(s) and the source, provide a link to the Creative Commons licence, and indicate if changes were made. The images or other third party material in this article are included in the article's Creative Commons licence, unless indicated otherwise in a credit line to the material. If material is not included in the article's Creative Commons licence and your intended use is not permitted by statutory regulation or exceeds the permitted use, you will need to obtain permission directly from the copyright holder. To view a copy of this licence, visit http://creativecommons.org/licenses/by/4.0/. The Creative Commons Public Domain Dedication waiver (http://creativecommons.org/publicdomain/zero/1.0/) applies to the data made available in this article, unless otherwise stated in a credit line to the data. 
day, which represents the fastest rate of cartilaginous tissue growth in the mammal kingdom [11].

Antler growth is driven by the growth center that is located in the distal tip consisted of mesenchyme and cartilage tissues [12]. According to the application of deer antler in traditional Chinese medicine, the antler is divided into wax slice, powder slice, blood slice, and bone slice from distal tip to proximal base, and the wax slice is located in the distal tip of antler (growth center), which has the highest percentage of bioactive components [13, 14]. In our previous studies, we generated the deer antler extract (DAE), and the proportion of protein was $70 \%$ according to the protein concentration assay [15].

We also performed a series of analyses to investigate the effects of deer antler extract (DAE) on chondrocyte proliferation, differentiation, and apoptosis and demonstrated that freshly aqueous extracts from sika deer antlers at rapid growth stage could enhance chondrocyte viability and promote chondrocyte proliferation, but inhibit chondrocyte differentiation, maturation, and apoptosis. Furthermore, our results suggested that DAE play potential roles in boosting the abilities of chondrocytes against oxidative, inflammatory, and immune stresses $[15,16]$.

In the present study, we carried out state-of-the-art RNA sequencing (RNA-seq) experiment combined with quantitative real-time polymerase chain reaction (qRTPCR) verification assay to explore the molecular control and therapeutic targets of DAE on articular cartilage. We demonstrated that DAE significantly increased the expression levels of functional genes involved in cartilage formation, growth, and repair and decreased the expression levels of susceptibility genes involved in the pathophysiology of osteoarthritis. Thus, DAE might serve as a candidate supplement for maintaining cartilage homeostasis and preventing cartilage degeneration and inflammation. These effects were possibly achieved by accelerating the expression of functional genes involved in chondrocyte commitment, survival, proliferation, and differentiation and suppressing the expression of susceptibility genes involved in the pathophysiology of osteoarthritis.

\section{Methods}

\section{DAE preparation}

The DAE used in the following experiments was the same as the ones that were prepared as previously described [15]. All experiments were approved by the Institutional Animal Ethics Committee of Changchun University of Chinese Medicine. Briefly, deer antlers in the rapid growth phase were obtained from three 4-year-old adult sika deers. The antlers were chopped into small pieces and thoroughly washed with ice water. The clean antler pieces were completely homogenized with a Tissue Homogenizer (Voshin, China) and centrifuged with an Eppendorf 5804R Refrigerated Centrifuge (Eppendorf, Germany). The supernatant was further clarified by filtering through a Hollow Fiber Membrane Filter Column (GE Healthcare, USA) and lyophilized with a Heto PowerDry LL3000 Freeze Dryer prior to storage at $-80^{\circ} \mathrm{C}$ (Thermo, USA).

\section{Experimental animals}

Twenty male Sprague-Dawley (SD) rats (SPF grade, 7 weeks old) were obtained from the Changchun Yisi laboratory animal technology Co, Ltd. (Changchun, China) with production license number SCXK (Ji) 2016-0003. The rats were housed with a constant temperature of $23^{\circ} \mathrm{C}$ accompanied with a relative humidity of $50 \%$ in an air-conditioned room and exposed to a 12/12-h (light/ dark) cycle. All animal protocols were approved by the Institutional Animal Care and Use Committee of Changchun University of Chinese Medicine, and all experimental procedures were performed in accordance with corresponding standards and guidelines.

\section{Drug administration and cartilage collection}

All rats were randomly divided into Blank group and DAE group (10 rats per group) after 7-day adaptive feeding. The drug administration was carried out as previously described [5]. The rats in DAE group were orally administrated with DAE at a dose of $0.2 \mathrm{~g} / \mathrm{kg}$ per day for 3 weeks, and the rats in Blank group were fed with drinking water. The administrated dose for DAE in rat experiment was calculated based on the body surface area normalization method [17]. Articular cartilage from each rat was harvested in the early morning after 3 weeks of DAE administration. Briefly, all rats were euthanized with $\mathrm{CO}_{2}$ inhalation and cervical dislocation to assure death. Articular cartilage from either the Blank group or the DAE group was carefully removed from the underlying subchondral bone from the left knee joint with a scalpel blade accompanied with a stereo microscope (Nikon, Japan) following Katagiri's methods [18] and stored at $-80^{\circ} \mathrm{C}$ for RNA extraction.

\section{RNA isolation and sequencing}

Cartilage from each group was pooled together and pulverized into a powder in liquid nitrogen, respectively. Total RNA was isolated from the cartilage samples with the TRIzol reagent (Invitrogen, USA) according to the manufacturer's instructions. The quality of RNA was assessed using an Agilent 2100 Bioanalyzer (Agilent Technologies, USA). Illumina $2 \times 150$ paired-end mRNA libraries were prepared with the TruSeq Stranded mRNA kit (Illumina, USA) according to the manufacturer's instructions. Transcriptome sequencing was carried out by RNA-seq method on an Illumina HiSeq 2500 platform (Illumina, USA). 


\section{RNA-seq data analysis}

After RNA-seq, raw reads in FASTQ format were first processed by perl scripts. High-quality clean reads were generated by removing the low-quality reads and adapter sequences. The clean reads from each sample were aligned to the rat (Rattus norvegicus) reference genome via HISAT software [19]. Gene expression levels were evaluated by calculating the relative transcript abundance using the FPKM algorithm [20]. Genes with an FPKM smaller than 0.2 were considered not expressed and removed [21]. The transcripts were annotated using the BLAST program against the National Center for Biotechnology Information (NCBI) non-redundant (NR) and Swiss-Prot protein databases [22]. Differentially expressed genes (DEGs) between the Blank group and DAE group were identified using the DEGseq $R$ package [23]. Transcripts with a $\log _{2}$ fold change $\geq 1$ or $\leq-1$ and with a $p$ value $\leq 0.001$ were defined as DEGs. Gene ontology (GO) and Kyoto Encyclopedia of Genes and Genomes (KEGG) enrichment was analyzed using an R function phyper, and the hypergeometric test and Bonferroni correction were carried out for multiple testing corrections. GO terms or pathways with an adjusted $p$ value $(\mathrm{Q}$ value) less than 0.05 were recognized to be significantly enriched [24].

\section{Verification of RNA-seq data by qRT-PCR}

To verify the RNA-seq data, qRT-PCR was carried out to detect the expression levels of DEGs identified by RNAseq analysis. Briefly, total RNA was isolated using TRIzol reagent (Invitrogen, USA) following the manufacturer's instructions. cDNA synthesis was performed using an iScript cDNA Synthesis Kit (Bio-Rad, USA) and amplified using a SsoAdvanced Universal SYBR ${ }^{\circ}$ Green Supermix (Bio-Rad, USA) on a CFX Connect Real-Time PCR Detection System (Bio-Rad, USA) under standard amplification conditions. Gene expression levels were calculated according to the $2^{-\triangle \Delta C T}$ method by normalizing the rat glyceraldehyde 3-phosphate dehydrogenase gene (Gapdh) [25].

\section{Results}

\section{Statistic summary of RNA-seq data}

The messenger RNAs (mRNAs) of articular cartilage from rats with or without the treatment of DAE were sequenced using Illumina paired-end sequencing technology. The raw reads were uploaded in the NCBI Sequence Read Archive (SRA) database under BioProject accession number PRJNA642711. As shown in Table 1, 39,698,758 (Blank group) and 40,202,822 (DAE group) clean reads were obtained after trimming away the lowquality and adapter sequences, respectively, and the quality control results showed that the Q30 value was greater than $94 \%$, and the GC content was around $51 \%$. Therefore, the sequencing results were accurate and
Table 1 Overview of output statistics of sequencing and assembly

\begin{tabular}{lll}
\hline Statistics & Blank & DAE \\
\hline Clean reads & $39,698,758$ & $40,202,822$ \\
Q30 percentage & 94.78 & 94.86 \\
GC percentage & 51.27 & 51.84 \\
Total mapped reads & $37,619,438$ & $38,032,508$ \\
Total transcripts & 15,664 & 15,733 \\
Known transcripts & 12,821 & 12,902 \\
\hline
\end{tabular}

reliable for further analysis. By performing data mapping and annotation, 37,619,438 (Blank group) and 38,032, 508 (DAE group) reads were mapped to the rat (Rattus norvegicus) genome; subsequently, 12,821 out of 15,664 (Blank group) and 12,902 out of 15,733 (DAE group) transcripts were obtained by annotating against the nonredundant (NR) NCBI protein database and Swiss-Prot database, respectively.

\section{DEGs identification, GO and KEGG enrichment analysis}

By comparing the Blank group and DAE group, 308 genes were identified as DEGs under the established criteria ( $\log _{2}$ fold change $\geq 1$ or $\leq-1$ and $p \leq 0.001$ ), including 208 upregulated genes $\left(\log _{2}\right.$ fold change $\geq 1$ and $p \leq 0.001)$ and 100 downregulated genes $\left(\log _{2}\right.$ fold change $\leq-1$ and $p \leq 0.001$ ), as shown in Table 2. GO enrichment analyses were carried out to gain insight into the biological functions of DEGs under DAE treatment, as shown in Fig. 1. Under the category of cellular component, the significantly enriched GO terms were mainly classified into extracellular region, extracellular region part, extracellular space, extracellular matrix, and proteinaceous extracellular matrix; under the category of molecular function, the significantly enriched GO terms were mainly classified into protein binding, transporter activity, substrate-specific transporter activity, protein heterodimerization activity, and tetrapyrrole binding; under the category of biological process, the significantly enriched GO terms were mainly classified into singlemulticellular organism process, developmental process, single-organism developmental process, anatomical structure development, and multicellular organism development. KEGG pathway enrichment analyses were carried out to further explore the possible functional pathways of DEGs under DAE treatment, as shown in

Table 2 Statistics for the differentially expressed genes (DAE vs. Blank)

\begin{tabular}{ll}
\hline Statistics & Number \\
\hline Differentially expressed mRNAs & 308 \\
Upregulated mRNAs & 208 \\
Downregulated mRNAs & 100 \\
\hline
\end{tabular}




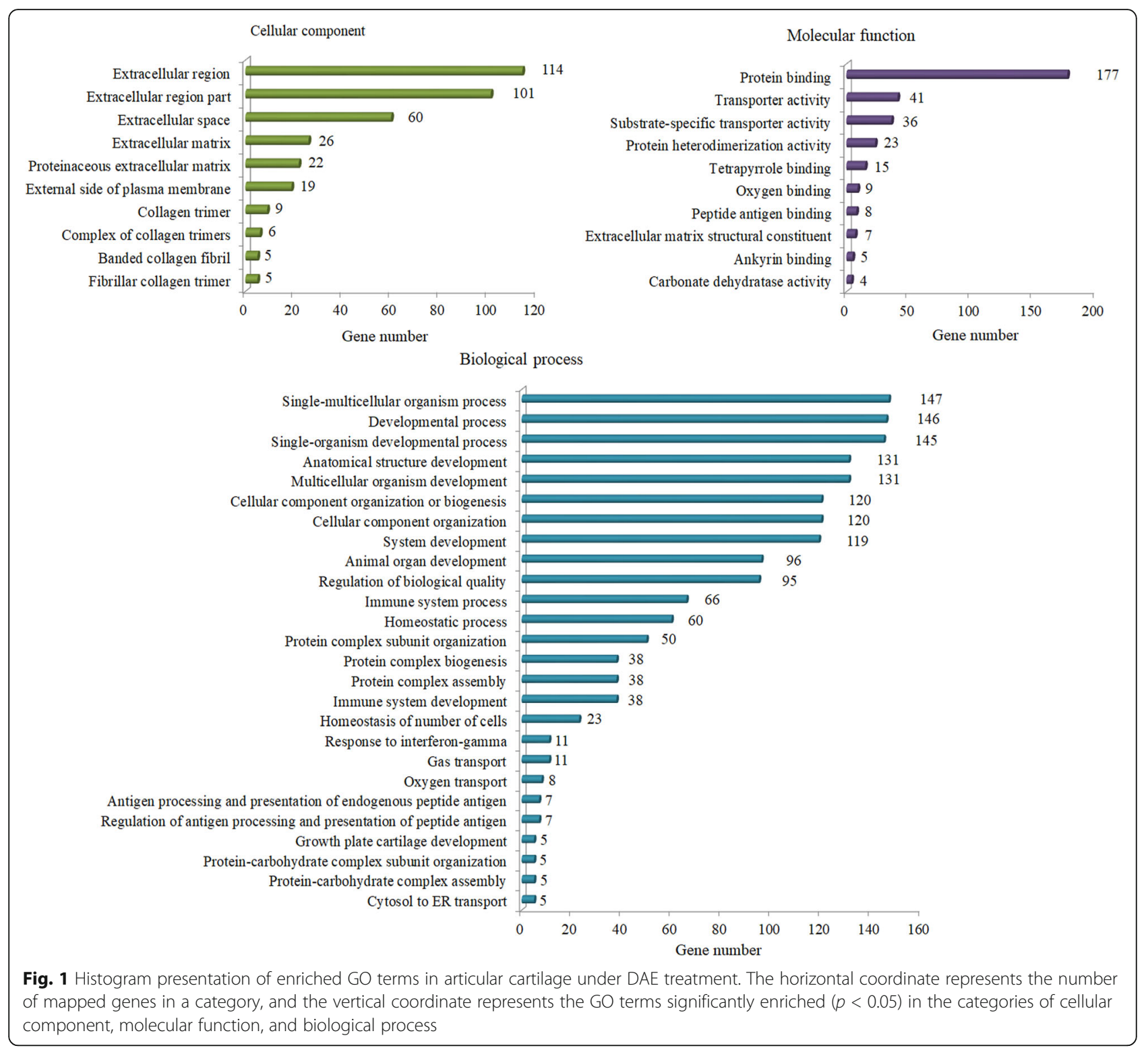

Fig. 2; the significant enriched pathways were predominantly mapped to thyroid hormone signaling pathway, protein digestion and absorption, PI3K-AKT signaling pathway, nitrogen metabolism, ECM-receptor interaction, and cell adhesion molecules (CAMs).

DAE significantly increased the expression levels of functional genes involved in cartilage formation, growth, and repair

According to the analysis of DEGs, 36 genes involved in cartilage formation, growth, and repair were identified, such as hyaluronan and proteoglycan link protein 1 (Hapln1), collagen alpha-1(IX) chain (Col9a1), scrapieresponsive protein 1 ( $\mathrm{Scrg} 1)$, cartilage oligomeric matrix protein (Comp), leukocyte cell-derived chemotaxin 1 (Cnmd), carbonic anhydrase 2 (Ca2), matrilin-3 (Matn3), transferrin receptor protein 1 (Tfrc), vascular endothelial growth factor A (Vegfa), and collagen alpha-1(XXVII) chain (Col27a1), as shown in Table 3.

\section{DAE significantly decreased the expression levels of susceptibility genes involved in the pathophysiology of osteoarthritis}

According to the analysis of DEGs, 31 genes involved in osteoarthritis susceptibility were identified, such as collagen alpha-1(I) chain (Col1a1), protein S100-A4 (S100a4), fatty acid-binding protein (Fabp4), collagen alpha-1(IV) chain (Col4a1), cyclic AMP-responsive element-binding protein 3-like protein 1 (Creb3l1), C-C motif chemokine 9 (Ccl9), retinoid-binding protein 7 ( $\mathrm{Rbp} 7)$, neurogenic locus notch homolog protein 3 (Notch3), C-X-C motif chemokine 16 (Cxcl16), and receptor activity-modifying protein 3 (Ramp3), as shown in Table 4. 


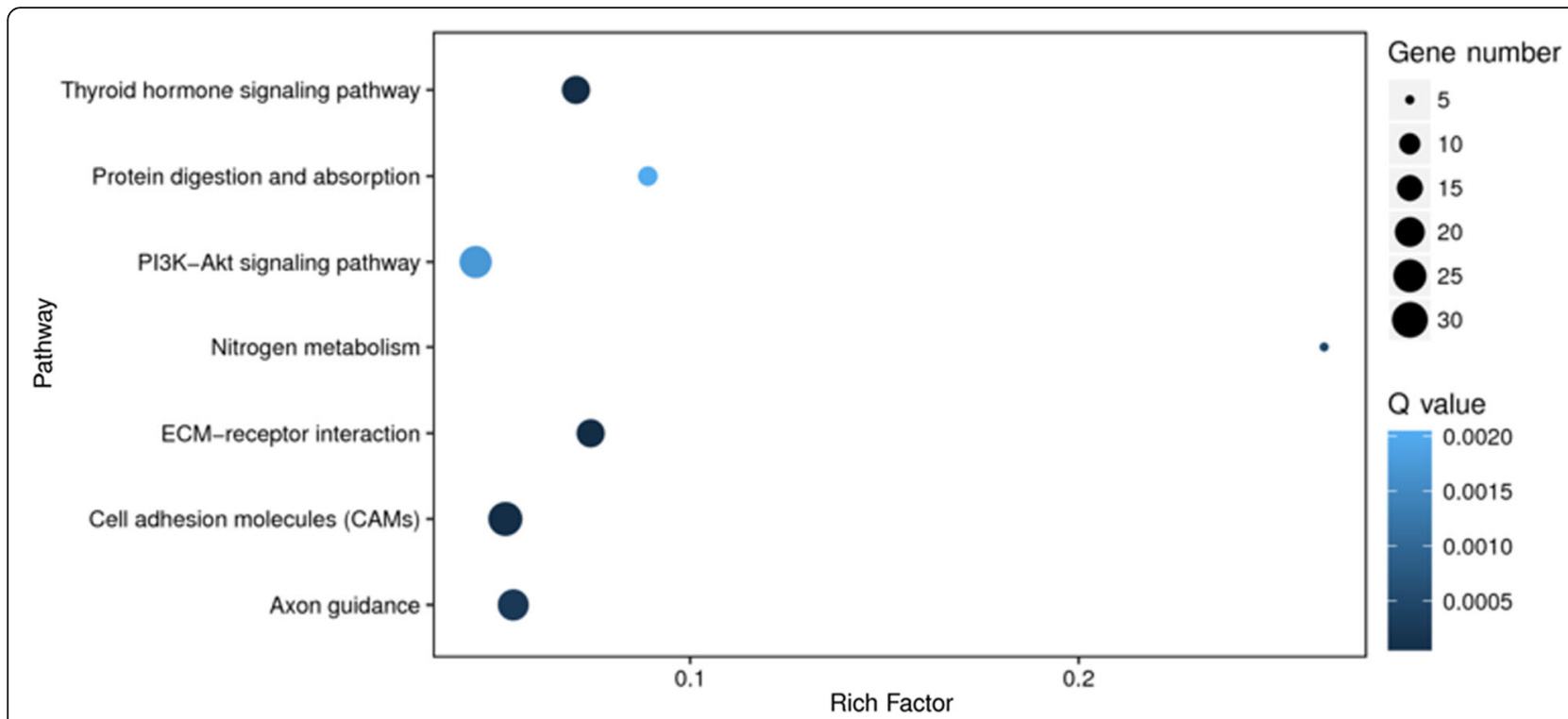

Fig. 2 Scatter plot of enriched KEGG pathways in articular cartilage under DAE treatment. The horizontal coordinate represents the rich factor that is calculated as the ratio of the number of DEGs divided by the total gene number in a certain pathway, and the vertical coordinate represents the enriched pathway. The color and size of the dots represent the range of the $\mathrm{Q}$ values and the number of DEGs mapped to a certain pathway, respectively

\section{Gene expression levels of DEGs validated by qRT-PCR}

The expression levels of a series of DEGs were validated by qRT-PCR assay, including 6 significantly upregulated genes and 6 significantly downregulated genes. The specific gene primers for qRT-PCR were listed in Table 5 . The relative fold change of each gene was normalized to the internal reference gene Gapdh. The expression levels of the selected DEGs validated by qRT-PCR exhibited similar expression patterns as those of the RNA-seq analysis, as shown in Fig. 3.

\section{Discussion}

For many years, RNA-seq has become an essential tool for studying the dynamic and complex characteristics of the transcriptome, especially for the mRNA molecules, which encode proteins following the central dogma of molecular biology [26, 27]. Meanwhile, many scientists in the research field of Chinese medicine have paid more and more attention to explore the molecular control of Chinese herbs and formulations by taking advantage of RNA-seq technology [28, 29]. Our previous studies have shown that DAE play potential roles in regulating chondrocyte proliferation and differentiation $[15,16]$. Therefore, in the present study, we further investigated the effects of DAE on articular cartilage using a state-of-theart RNA-seq technology accompanied with validation method to obtain the precise molecular mechanism of DAE on cartilage homeostasis.

In total, 308 DEGs were identified, including 208 upregulated genes and 100 downregulated genes by comparing DAE-treated group with Blank group (DAE vs.
Blank). According to the GO enrichment analysis, the significantly enriched GO terms were predominantly involved in extracellular matrix synthesis, binding activity, and developmental process. Those functional gene groups play pivotal roles in regulating cartilage homeostasis [30-32]. Based on the KEGG enrichment analysis, the significantly enriched pathways were predominantly involved in thyroid hormone signaling pathway, protein digestion and absorption, PI3K-AKT signaling pathway, nitrogen metabolism, ECM-receptor interaction, and cell adhesion molecules (CAMs). Among those enriched signaling pathways, thyroid hormone signaling pathway, PI3K-AKT signaling pathway, ECM-receptor interaction, and cell adhesion molecules (CAMs) have been considered to play crucial roles in articular cartilage maintenance and osteoarthritis pathogenesis [33-36]. Thus, these results suggest that DAE play potential role in regulating articular cartilage homeostasis by controling multiple functional group genes and signaling pathways.

Among the significantly upregulated DEGs under DAE treatment, 36 genes that participate in cartilage formation, growth, and repair were identified. For instance, Hapln1, Col9a1, Comp, Cnmd, Matn3, Col27a1, Matn1, and Dpt are extracellular matrixes that play key roles in regulating chondrocyte metabolism and functions via cell-matrix interaction [37-41]. Scrg1 is a stimulator of chondrogenesis that has a potential role in tissue engineering of articular cartilage [42]. Tfrc, also known as CD71, is a transferrin receptor that is essential for cartilage maturation during embryonic development [43]. Vegfa, a member of the Vegf growth factor family, is a key component 
Table 3 List of significantly upregulated DEGs involved in cartilage formation, growth, and repair

\begin{tabular}{|c|c|c|c|c|}
\hline \multirow[t]{2}{*}{ Gene name } & \multicolumn{2}{|c|}{ Expression level (FPKM) } & \multirow{2}{*}{$\begin{array}{l}\log _{2} \\
\text { fold } \\
\text { change } \\
\text { (DAE/ } \\
\text { Blank) }\end{array}$} & \multirow[t]{2}{*}{$p$ value } \\
\hline & Blank & DAE & & \\
\hline Hyaluronan and proteoglycan link protein 1 (Hapln1) & 301.97 & 901.64 & 1.58 & 0 \\
\hline Collagen alpha-1(IX) chain (Col9a1) & 142.16 & 519.76 & 1.87 & 0 \\
\hline Scrapie-responsive protein 1 (Scrg1) & 203.52 & 491.32 & 1.27 & $1.23 \mathrm{E}-92$ \\
\hline Cartilage oligomeric matrix protein (Comp) & 230.34 & 490.17 & 1.09 & 0 \\
\hline Leukocyte cell-derived chemotaxin 1 (Cnmd) & 135.34 & 397.34 & 1.55 & $1.08 \mathrm{e}-321$ \\
\hline Carbonic anhydrase 2 (Ca2) & 172.19 & 352.43 & 1.03 & $2.61 \mathrm{E}-159$ \\
\hline Matrilin-3 (Matn3) & 112.11 & 292.66 & 1.38 & 0 \\
\hline Transferrin receptor protein 1 (Tfrc) & 46.77 & 117.84 & 1.33 & 1.65E-274 \\
\hline Vascular endothelial growth factor A (Vegfa) & 51.06 & 107.19 & 1.07 & 8.57E-143 \\
\hline Collagen alpha-1(XXVII) chain (Col27a1) & 41.63 & 90.66 & 1.12 & $2.44 \mathrm{E}-248$ \\
\hline M-phase inducer phosphatase 2 (Cdc25b) & 33.93 & 76.00 & 1.16 & $1.82 \mathrm{E}-92$ \\
\hline Proliferation marker protein Ki-67 (Mki67) & 21.76 & 45.38 & 1.06 & $6.36 \mathrm{E}-136$ \\
\hline Carbonic anhydrase 12 (Ca12) & 10.53 & 35.95 & 1.77 & 2.03E-95 \\
\hline Radical S-adenosyl methionine domain-containing protein 2 (Rsad2) & 9.91 & 29.91 & 1.59 & $1.27 \mathrm{E}-69$ \\
\hline T cell acute lymphocytic leukemia protein 1 homolog (Tal1) & 10.64 & 23.50 & 1.14 & 2.07E-44 \\
\hline Chondroitin sulfate $\mathrm{N}$-acetylgalactosaminyltransferase 1 (Csgalnact1) & 11.15 & 22.80 & 1.03 & $3.03 \mathrm{E}-18$ \\
\hline Cartilage matrix protein (Matn1) & 4.78 & 21.71 & 2.18 & $3.49 \mathrm{E}-40$ \\
\hline Chordin-like protein 1 (Chrdl1) & 7.49 & 19.15 & 1.35 & $2.56 \mathrm{E}-41$ \\
\hline Thrombospondin-3 (Thbs3) & 5.25 & 16.71 & 1.67 & $7.21 \mathrm{E}-37$ \\
\hline Complement decay-accelerating factor, GPI-anchored (Cd55) & 7.74 & 15.89 & 1.04 & $1.04 \mathrm{E}-10$ \\
\hline Mitotic checkpoint serine/threonine-protein kinase BUB1 (Bub1) & 7.32 & 14.81 & 1.02 & $4.70 \mathrm{E}-23$ \\
\hline G1/S-specific cyclin-E2 (Ccne2) & 6.42 & 14.00 & 1.12 & $1.48 \mathrm{E}-17$ \\
\hline Protein MGARP (Mgarp) & 4.50 & 12.66 & 1.49 & $1.12 \mathrm{E}-09$ \\
\hline M-phase phosphoprotein 8 (Mphosph8) & 5.78 & 12.46 & 1.11 & $2.24 \mathrm{E}-14$ \\
\hline Noggin (Nog) & 4.80 & 11.69 & 1.28 & $7.67 \mathrm{E}-10$ \\
\hline Carbonic anhydrase 9 (Ca9) & 5.45 & 11.63 & 1.09 & $7.97 \mathrm{E}-10$ \\
\hline ESF1 homolog (Esf1) & 5.27 & 11.61 & 1.14 & $1.35 E-16$ \\
\hline Aryl hydrocarbon receptor nuclear translocator-like protein 1 (Arntl) & 3.14 & 10.98 & 1.81 & $2.48 \mathrm{E}-25$ \\
\hline $\mathrm{H}(+) / \mathrm{Cl}(-)$ exchange transporter 3 (Clcn3) & 4.15 & 9.18 & 1.15 & $1.12 \mathrm{E}-08$ \\
\hline G2/M phase-specific E3 ubiquitin-protein ligase (G2e3) & 3.80 & 7.66 & 1.01 & $2.15 E-13$ \\
\hline Dual specificity tyrosine-phosphorylation-regulated kinase 3 (Dyrk3) & 2.45 & 6.59 & 1.43 & 7.06E-09 \\
\hline Protein kinase C zeta type (Prkcz) & 2.98 & 6.32 & 1.08 & $5.86 \mathrm{E}-07$ \\
\hline WNT1-inducible-signaling pathway protein 3 (Wisp3) & 2.82 & 5.89 & 1.06 & $2.27 \mathrm{E}-06$ \\
\hline Centrosomal protein of $70 \mathrm{kDa}$ (Cep70) & 2.02 & 4.72 & 1.22 & $2.28 \mathrm{E}-08$ \\
\hline Dermatopontin (Dpt) & 1.46 & 3.97 & 1.44 & $3.09 \mathrm{E}-07$ \\
\hline Murinoglobulin-1 (Mug1) & 0.56 & 1.67 & 1.58 & $3.76 \mathrm{E}-06$ \\
\hline
\end{tabular}

to support chondrocyte survival [44]. Ca2, Ca12, and Ca9 are family members of carbonic anhydrases, which are important for cartilage homeostasis. All of them are significantly expressed in the articular chondrocytes, and $\mathrm{Ca} 2$ is mainly localized in the proliferating chondrocytes [45]. Rsad2, also known as viperin, is highly expressed in the middle zone of articular cartilage [46]. Tal1 is a basic helix-loop-helix transcription factor in the articular chondrocytes and serves as a crucial regulator during chondrocyte maturation [47].

Csgalnact1 is a glycosyltransferase that is necessary for the biosynthesis of chondroitin sulfate proteoglycans in 
Table 4 List of significantly downregulated DEGs involved in osteoarthritis susceptibility

\begin{tabular}{|c|c|c|c|c|}
\hline \multirow[t]{2}{*}{ Gene name } & \multicolumn{2}{|c|}{ Expression level (FPKM) } & \multirow{2}{*}{$\begin{array}{l}\log _{2} \\
\text { fold change (DAE/Blank) }\end{array}$} & \multirow[t]{2}{*}{$p$ value } \\
\hline & Blank & DAE & & \\
\hline Collagen alpha-1(I) chain (Col1a1) & 6244.47 & 2741.45 & -1.19 & 0 \\
\hline Protein S100-A4 (S100a4) & 687.97 & 330.60 & -1.06 & $2.85 \mathrm{E}-77$ \\
\hline Fatty acid-binding protein (Fabp4) & 150.74 & 74.48 & -1.02 & $1.22 \mathrm{E}-22$ \\
\hline Collagen alpha-1(IV) chain (Col4a1) & 60.42 & 26.01 & -1.22 & $1.55 \mathrm{E}-166$ \\
\hline $\begin{array}{l}\text { Cyclic AMP-responsive element-binding protein } \\
\text { 3-like protein } 1 \text { (Creb311) }\end{array}$ & 53.52 & 23.54 & -1.18 & $1.14 \mathrm{E}-56$ \\
\hline C-C motif chemokine 9 (Cc|9) & 34.51 & 11.42 & -1.60 & $2.15 \mathrm{E}-27$ \\
\hline Retinoid-binding protein 7 (Rbp7) & 19.22 & 5.96 & -1.69 & $1.21 \mathrm{E}-07$ \\
\hline Neurogenic locus notch homolog protein 3 (Notch3) & 18.11 & 8.55 & -1.08 & $1.69 \mathrm{E}-47$ \\
\hline C-X-C motif chemokine 16 (Cxcl16) & 17.30 & 7.62 & -1.18 & $1.19 E-12$ \\
\hline Receptor activity-modifying protein 3 (Ramp3) & 16.14 & 6.77 & -1.25 & $2.83 \mathrm{E}-09$ \\
\hline Cytochrome P450 1B1 (Cyp1b1) & 15.63 & 6.84 & -1.19 & $1.50 \mathrm{E}-15$ \\
\hline $\begin{array}{l}\text { Proprotein convertase subtilisin/kexin type } 1 \text { inhibitor } \\
\text { (Pcsk1n) }\end{array}$ & 15.53 & 6.80 & -1.19 & 1.73E-06 \\
\hline Homeobox protein DLX-3 (D/x3) & 15.49 & 7.31 & -1.08 & $3.27 \mathrm{E}-15$ \\
\hline Protein naked cuticle homolog 2 (Nkd2) & 14.53 & 6.59 & -1.14 & $1.00 \mathrm{E}-22$ \\
\hline Matrix metalloproteinase-19 (Mmp19) & 12.71 & 6.07 & -1.07 & $2.53 \mathrm{E}-09$ \\
\hline Endosialin (Cd248) & 11.69 & 5.06 & -1.21 & $2.00 \mathrm{E}-13$ \\
\hline Pentraxin-related protein PTX3 (Ptx3) & 10.83 & 5.32 & -1.03 & $1.16 \mathrm{E}-07$ \\
\hline Fc receptor-like protein 2 (Fcrl2) & 10.76 & 4.82 & -1.16 & $1.76 \mathrm{E}-10$ \\
\hline Serine protease HTR4 (Htra4) & 10.74 & 4.32 & -1.31 & $2.14 \mathrm{E}-12$ \\
\hline $\begin{array}{l}\text { Transforming growth factor beta-1-induced transcript } 1 \\
\text { protein (Tgfb1i1) }\end{array}$ & 10.61 & 5.05 & -1.07 & $3.56 \mathrm{E}-08$ \\
\hline Apelin receptor (Aplnr) & 10.59 & 3.76 & -1.49 & $2.16 \mathrm{E}-23$ \\
\hline Tubulin beta-2B chain (Tubb2b) & 7.26 & 3.04 & -1.26 & $1.80 \mathrm{E}-06$ \\
\hline Arginase-1 (Arg1) & 5.65 & 2.37 & -1.25 & $8.66 \mathrm{E}-05$ \\
\hline Nostrin (Nostrin) & 5.43 & 2.16 & -1.33 & $1.80 \mathrm{E}-05$ \\
\hline von Willebrand factor (Vwf) & 3.76 & 1.63 & -1.21 & $3.03 \mathrm{E}-15$ \\
\hline Tenascin-X (Tnxb) & 2.82 & 1.27 & -1.15 & $4.95 \mathrm{E}-05$ \\
\hline Aryl hydrocarbon receptor (Ahr) & 2.41 & 1.16 & -1.05 & $1.62 \mathrm{E}-05$ \\
\hline $\begin{array}{l}\text { Interferon-induced protein with tetratricopeptide repeats } \\
1 \text { (Ifit1) }\end{array}$ & 2.01 & 0.54 & -1.90 & $1.02 \mathrm{E}-04$ \\
\hline Interleukin-2 receptor subunit beta (IIrb) & 1.91 & 0.59 & -1.69 & $1.31 \mathrm{E}-04$ \\
\hline Chloride intracellular channel protein 5 (Clic5) & 1.81 & 0.51 & -1.83 & $1.62 \mathrm{E}-09$ \\
\hline C-type lectin domain family 9 member A (Clec9a) & 1.47 & 0.43 & -1.77 & $9.17 \mathrm{E}-05$ \\
\hline
\end{tabular}

cartilage, particularly in the proliferating chondrocytes [48]. Chrdl1, a secreted glycoprotein, is considered to be a juvenile chondrocyte-specific factor that stimulates stem cell growth [49]. Thbs3 is mainly expressed in the proliferating chondrocytes and inhibits cartilage clarification [50]. Cd55 is a complement decay-accelerating factor in the cartilage that plays pivotal role in protecting chondrocytes from possible damage [51]. Nog serves as an inhibitor of bone morphogenetic proteins (BMPs) and prevents cartilage degeneration and osteoarthritis development by inhibiting Il1 $\beta$ and Bmp2 expression [52]. Esf1 is an essential nucleolar protein that is required for cartilage formation [53]. Arntl, also known as Bmal1, plays crucial role in controling cartilage homeostasis through modulating TGF- $\beta$ signaling [54]. Clcn3 is a highly expressed channel protein in chondrocytes during cartilage development and plays a key role in cell volume regulation [55]. Wisp3 is a multi-domain protein that maintains cartilage integrity and prevents chondrocyte hypertrophy [56]. Mug1 serves as an inhibitor of 
Table 5 List of primers used for qRT-PCR validation

\begin{tabular}{|c|c|c|}
\hline Gene & Primer & Sequence \\
\hline \multirow[t]{2}{*}{ Hapln1 } & Forward primer & GACAGCTACACTCCGGATCA \\
\hline & Reverse primer & AGCCAAATGCTGTAGGGTCT \\
\hline \multirow[t]{2}{*}{ Col9a1 } & Forward primer & CCAGCACATCAAGCAGGTTT \\
\hline & Reverse primer & CCTCCCAGGAAGACCAGAAG \\
\hline \multirow[t]{2}{*}{ Scrg1 } & Forward primer & CCTTGTCATCCTCGGGCTAA \\
\hline & Reverse primer & AACAGGAGAGGCGACTTGAA \\
\hline \multirow[t]{2}{*}{ Comp } & Forward primer & CAGCTCAAGGCTGTCAAGTC \\
\hline & Reverse primer & CTTCCAGCCCACATTTCGAG \\
\hline \multirow[t]{2}{*}{ Cnmd } & Forward primer & TTACCACCAGCAGGAAGGAG \\
\hline & Reverse primer & TGAGCGACACCCTTGGTAAT \\
\hline \multirow[t]{2}{*}{$\mathrm{Ca} 2$} & Forward primer & TCCTTGCTCCCTTCTTCCTG \\
\hline & Reverse primer & CAGGTCACACATTCCAGCAG \\
\hline \multirow[t]{2}{*}{ Col1a1 } & Forward primer & ACCTCAGGGTATTGCTGGAC \\
\hline & Reverse primer & GACCAGGGAAGCCTCTTTCT \\
\hline \multirow[t]{2}{*}{ S100a4 } & Forward primer & GCTGCATTCCAGAAGCTGAT \\
\hline & Reverse primer & CATCATGGCAATGCAGGACA \\
\hline \multirow[t]{2}{*}{ Fabp4 } & Forward primer & ATGTGCAGAAGTGGGATGGA \\
\hline & Reverse primer & GTCACGCCTTTCATGACACA \\
\hline \multirow[t]{2}{*}{ Col4a1 } & Forward primer & CCTCCAGGAACGACTACTCC \\
\hline & Reverse primer & GCACACCTGCTAATGAAGGG \\
\hline \multirow[t]{2}{*}{ Creb3l1 } & Forward primer & CAGCTGCAGAAACTCCAGAC \\
\hline & Reverse primer & CCAGAACAAAGCACAAGGCT \\
\hline \multirow[t]{2}{*}{ Ccl9 } & Forward primer & TCGTACATGCGACAGAGACA \\
\hline & Reverse primer & TGGACCCGTGAGGTATAGGA \\
\hline
\end{tabular}

proteolytic enzyme that prevents the degradation of cartilage extracellular matrix [57]. In addition, Cdc25b, Mki67, Bub1, Ccne2, Mphosph8, G2e3, Dyrk3, and Cep70 are considered to be essential genes involved in cell proliferation [58-64]. Thus, these results suggest that DAE might serve as a candidate supplement for maintaining cartilage homeostasis.

Among the significantly downregulated DEGs under DAE treatment, 31 genes involved in osteoarthritis susceptibility were identified. For instance, Colla1 and Col4a1 are collagen fibers that were associated with the progression of osteoarthritis [65]. S100a4, a member of the $\mathrm{S} 100$ protein family, is involved in cartilage degradation of osteoarthritis pathophysiology [66]. Fabp4 is a fatty acid-binding protein that serves as a biomarker for knee osteoarthritis [67]. Creb3l1 is a transcription factor significantly upregulated at the early stage of osteoarthritis [68]. Ccl9, also called

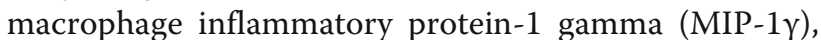
is a small cytokine belonging to the $\mathrm{CC}$ chemokine family that was shown to be highly expressed during osteoarthritis progression [69]. Rbp7, a family member of the cellular retinol-binding proteins, is significantly upregulated in osteoarthritic chondrocytes [70]. Notch3 is a family member of Notch receptors, and genetic deletion of Notch3 or the blockade of Notch3 signaling prevents joint damage and attenuates inflammation of inflammatory arthritis [71].

Cxcl16 (a chemokine ligand), Cd248 (a transmembrane glycoprotein), Ptx3 (an inflammation induced gene), Fcrl2 (a subtype of Fc receptor-like molecules), Tgfbli1 (a transforming growth factor beta 1 induced gene), Nostrin (a nitric oxide synthase traffic inducer), Vwf (an adhesive and multimeric glycoprotein), Tnxb (a member of the tenascin family), Ahr (a ligand-activated transcription factor), Ifit1 (an interferon-induced protein), Il2rb (an interleukin-2 receptor subunit), and Clec9a (a C-type lectin) are involved in the inflammation associated with arthritis pathology [72-83]. Ramp3 is a receptor activity-modifying protein that is highly expressed during joint inflammation [84]. Cyp1b1 (a member of the cytochrome P450 enzyme family), Pcsk1n (an inhibitor of prohormone convertase 1), Dlx3 (a family member of homeobox proteins), Nkd2 (a regulator of inflammatory response), Mmp19 (a subtype of matrix metalloproteinases), Htra4 (a subtype of serine proteases), Aplnr (a G protein-coupled receptor of apelin), Tubb2b (a beta isoform of tubulin), Arg1 (a cytosolic manganese-dependent enzyme), and Clic5 (a chloride intracellular channel protein) are reported to be highly expressed under osteoarthritic condition [85-94]. Thus, these results suggest that DAE might serve as a candidate supplement for preventing cartilage degeneration and inflammation.

In addition to the above findings, we also compared the expression levels of genes that are well known to characterize hyaline cartilage, such as Sox9, Sox5, Sox6, Wwp2, Acan, Col2a1, Col9a1, Col11a1, Hapln1, Comp, Matn1, Ptch1, Fgfr3, Runx2, and Runx3. As shown in Table S1, the expression levels of a majority of these genes were slightly upregulated under the DAE treatment. However, the expression level of Sox9 was slightly downregulated, which indicates that DAE might regulate articular chondrocytes through other transcription factors and related signaling pathways.

Nevertheless, there are still some limitations in the present study. First, this study lacks pathological analysis of animal model by performing the histological, behavioral, and biochemical evaluations; further experiments in the future still need to be carried out to investigate the effects of DAE on osteoarthritis model to get insight into their exact roles in regulating cartilage repair and regeneration. Second, this study included only a small sample size, although it is very difficult to obtain enough qualified articular cartilage 

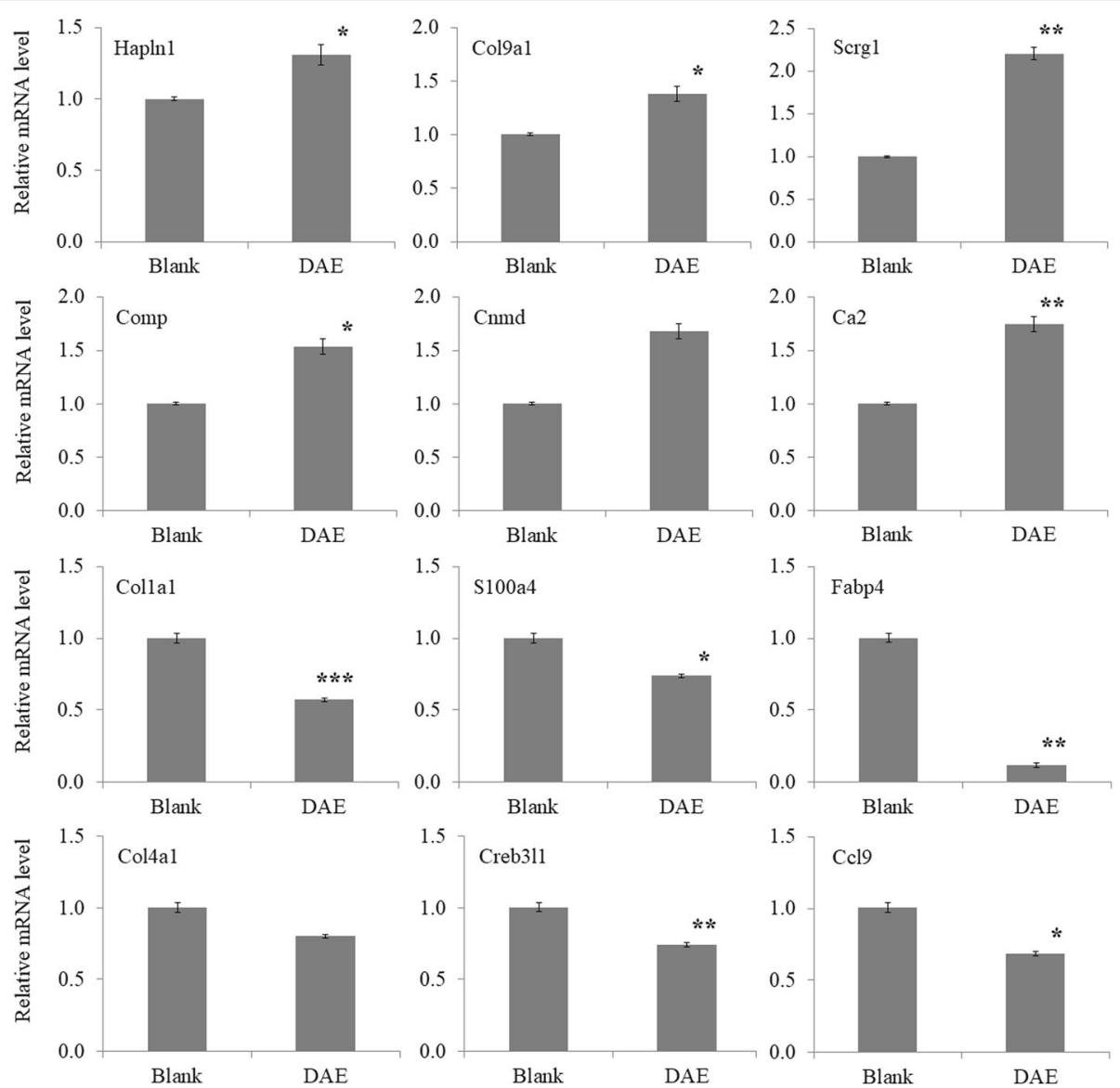

Fig. 3 gRT-PCR validation of RNA-seq data. Data shown are representative of multiple independent experiments $(n=3)$ with biological triplicates per experiment with their corresponding standard deviation. The asterisk ${ }^{*},{ }^{* *}$, and ${ }^{* * *}$ indicate significant differences using the Student $t$ test with $p$ value $<0.05,<0.01$, and $<0.001$, respectively. Gene expression levels for individual genes are presented as the ratio of (fold change) the DAE group to the Blank group

from rats, which largely limits the sample size. However, more sample sizes still need to be included in future studies, and it is better to have at least 3 to 5 independent tissue samples be independently assessed for statistical analysis of a molecular outcome.

\section{Conclusion}

In summary, the present study demonstrated that DAE might serve as a candidate supplement for maintaining cartilage homeostasis and preventing cartilage degeneration and inflammation. These effects were possibly achieved by accelerating the expression of functional genes involved in cartilage formation, growth, and repair and suppressing the expression of susceptibility genes involved in the pathophysiology of osteoarthritis. Thus, our findings will contribute towards deepening the knowledge about the molecular control and therapeutic targets of DAE on the treatment of cartilage-related diseases.

\section{Supplementary Information}

The online version contains supplementary material available at https://doi. org/10.1186/s13018-020-02148-w.

\section{Additional file 1: Table S1.}

\section{Abbreviations}

DAE: Deer antler extract; SD: Sprague-Dawley; RNA-seq: RNA sequencing; GO: Gene ontology; KEGG: Kyoto Encyclopedia of Genes and Genomes; DEGs: Differentially expressed genes; NCBI: National Center for Biotechnology Information; NR: Non-redundant; SRA: Sequence Read Archive; qRT-

PCR: Quantitative real-time PCR; Gapdh: Glyceraldehyde 3-phosphate dehydrogenase; mRNAs: Messenger RNAs

\section{Acknowledgements}

Not applicable

\section{Authors' contributions}

$\mathrm{BY}, \mathrm{XL}$, and $\mathrm{DZ}$ conceived and designed the work. BY and $\mathrm{XL}$ helped to coordinate support and funding. BY, ZZ, and MZ performed the experiments. $\mathrm{BY}$ analyzed the data and wrote the original draft. $\mathrm{BY}, \mathrm{XL}$, and $\mathrm{DZ}$ reviewed and revised the manuscript. The authors read and approved the final version of manuscript. 


\section{Funding}

This work was supported by the National Key Research and Development Program of China (Grant No. 2018YFC1706605), the National Natural Science Foundation of China (Grant No. 81973887 and 81702136), and the TCM Clinical Research Center for Bone diseases of Jilin Province (Grant No. 20180623048TC). The funding bodies provided financial support, and the awardees performed the research. The founding sponsor had no role in the design of the study; in the collection, analysis, and interpretation of data; and in writing the manuscript.

\section{Availability of data and materials}

The datasets used and/or analyzed during the current study are available from the corresponding author on reasonable request.

\section{Ethics approval and consent to participate}

All procedures were performed in accordance with the guidelines of the Institutional Animal Ethics Committee of Changchun University of Chinese Medicine (No. ccucm-2017-0015).

\section{Consent for publication}

Not applicable.

\section{Competing interests}

The authors declare that they have no competing interests.

\section{Author details}

${ }^{1}$ Jilin Ginseng Academy, Changchun University of Chinese Medicine, Changchun 130117, China. ${ }^{2}$ Innovation Practice Center, Changchun University of Chinese Medicine, Changchun 130117, China. ${ }^{3}$ The Affiliated Hospital of Changchun University of Chinese Medicine, Changchun 130117, China.

Received: 23 July 2020 Accepted: 2 December 2020

Published online: 06 January 2021

\section{References}

1. Chen J, Yang Y, Abbasi S, Hajinezhad D, Kontulainen S, Honaramooz A. The effects of elk velvet antler dietary supplementation on physical growth and bone development in growing rats. Evid Based Complement Alternat Med. 2015;2015:819520.

2. Yu Y, Jin Y, Wang F, Yan J, Qi Y, Ye M. Protein digestomic analysis reveals the bioactivity of deer antler velvet in simulated gastrointestinal digestion. Food Res Int. 2017;96:182-90.

3. Ren C, Gong W, Li F, Xie M. Pilose antler aqueous extract promotes the proliferation and osteogenic differentiation of bone marrow mesenchymal stem cells by stimulating the BMP-2/Smad1, 5/Runx2 signaling pathway. Chin J Nat Med. 2019;17(10):756-67.

4. Ren C, Gong W, Li F, Xie M. Protective and therapeutic effects of Pilose antler against kidney deficiency-induced osteoporosis. Cell Mol Biol (Noisyle-grand). 2019;65(5):24-31.

5. Yao B, Gao H, Liu J, Zhang M, Leng X, Zhao D. Identification of potential therapeutic targets of deer antler extract on bone regulation based on serum proteomic analysis. Mol Biol Rep. 2019;46(5):4861-72.

6. Liu G, Ma C, Wang P, Zhang P, Qu X, Liu S, Zhai Z, Yu D, Gao J, Liang J, Dai W, Zhou L, Xia M, Yang H. Pilose antler peptide potentiates osteoblast differentiation and inhibits osteoclastogenesis via manipulating the NF-KB pathway. Biochem Biophys Res Commun. 2017:491(2):388-95.

7. Kierdorf $U$, Kierdorf $H$. Deer antlers-a model of mammalian appendage regeneration: an extensive review. Gerontology. 2011;57(1):53-65.

8. Kierdorf U, Li C, Price JS. Improbable appendages: deer antler renewal as a unique case of mammalian regeneration. Semin Cell Dev Biol. 2009;20(5): 535-42.

9. Price J, Faucheux C, Allen S. Deer antlers as a model of Mammalian regeneration. Curr Top Dev Biol. 2005;67:1-48.

10. Price JS, Allen S, Faucheux C, Althnaian T, Mount JG. Deer antlers: a zoological curiosity or the key to understanding organ regeneration in mammals? J Anat. 2005;207(5):603-18.

11. Price J, Allen S. Exploring the mechanisms regulating regeneration of deer antlers. Philos Trans R Soc Lond B Biol Sci. 2004;359(1445):809-22.
12. Li C, Clark DE, Lord EA, Stanton JA, Suttie JM. Sampling technique to discriminate the different tissue layers of growing antler tips for gene discovery. Anat. Rec. 2002;268(2):125-30.

13. Sui Z, Zhang L, Huo Y, Zhang Y. Bioactive components of velvet antlers and their pharmacological properties. J Pharm Biomed Anal. 2014;87:229-40.

14. Jiang $C$, Jin $Y$, Zhao $X$, Yuan $Y$, Zhao Y, Huang L. Rapid and robust authentication of deer antler velvet product by fast PCR-RFLP analysis. Mitochondrial DNA A DNA Mapp Seq Anal. 2018;29(2):266-72.

15. Yao $B$, Zhang $M$, Leng $X$, et al. Antler extracts stimulate chondrocyte proliferation and possess potent anti-oxidative, anti-inflammatory, and immune-modulatory properties. In Vitro Cell Dev Biol Anim. 2018;54(6):439-48.

16. Yao $B$, Zhang M, Leng $X$, Zhao D. Proteomic analysis of the effects of antler extract on chondrocyte proliferation, differentiation and apoptosis. Mol Biol Rep. 2019;46(2):1635-48.

17. Reagan-Shaw S, Nihal M, Ahmad N. Dose translation from animal to human studies revisited. FASEB J. 2008;22(3):659-61.

18. Katagiri $H$, Mendes LF, Luyten FP. Definition of a critical size osteochondral knee defect and its negative effect on the surrounding articular cartilage in the rat. Osteoarthritis Cartilage. 2017;25(9):1531-40.

19. Kim D, Langmead B, Salzberg SL. HISAT: a fast spliced aligner with low memory requirements. Nat methods. 2015:12(4):357-60.

20. Trapnell C, Williams BA, Pertea G, Mortazavi A, Kwan G, van Baren MJ, Salzberg SL, Wold BJ, Pachter L. Transcript assembly and quantification by RNA-Seq reveals unannotated transcripts and isoform switching during cell differentiation. Nat Biotechnol. 2010;28(5):511-5.

21. Bar S, Schachter M, Eldar-Geva T, Benvenisty N. Large-scale analysis of loss of imprinting in human pluripotent stem cells. Cell Rep. 2017;19(5): 957-68.

22. Altschul SF, Gish W, Miller W, Myers EW, Lipman DJ. Basic local alignment search tool. J Mol Biol. 1990;215(3):403-10.

23. Wang L, Feng Z, Wang X, Wang X, Zhang X. DEGseq: an R package for identifying differentially expressed genes from RNA-seq data. Bioinformatics. 2010;26(1):136-8.

24. Tyebji S, Hannan AJ, Tonkin CJ. Pathogenic infection in male mice changes sperm small RNA profiles and transgenerationally alters offspring behavior. Cell Rep. 2020;31(4):107573.

25. Schmittgen TD, Livak KJ. Analyzing real-time PCR data by the comparative $C$ (T) method. Nat Protoc. 2008:3(6):1101-8.

26. Stark R, Grzelak M, Hadfield J. RNA sequencing: the teenage years. Nat Rev Genet. 2019;20(11):631-56.

27. Liu Y, Beyer A, Aebersold R. On the dependency of cellular protein levels on mRNA abundance. Cell. 2016;165(3):535-50.

28. Xin J, Zhang RC, Wang L, Zhang YQ. Researches on transcriptome sequencing in the study of traditional Chinese medicine. Evid Based Complement Alternat Med. 2017:2017:7521363.

29. Guo R, Luo X, Liu J, Liu L, Wang X, Lu H. Omics strategies decipher therapeutic discoveries of traditional Chinese medicine against different diseases at multiple layers molecular-level. Pharmacol Res. 2020;152:104627.

30. Kiyotake EA, Beck EC, Detamore MS. Cartilage extracellular matrix as a biomaterial for cartilage regeneration. Ann N Y Acad Sci. 2016;1383(1):139-59.

31. Acharya C, Yik JH, Kishore A, Van Dinh V, Di Cesare PE, Haudenschild DR. Cartilage oligomeric matrix protein and its binding partners in the cartilage extracellular matrix: interaction, regulation and role in chondrogenesis. Matrix Biol. 2014;37:102-11.

32. DeLise AM, Fischer L, Tuan RS. Cellular interactions and signaling in cartilage development. Osteoarthritis Cartilage. 2000;8(5):309-34.

33. Williams GR. Thyroid hormone actions in cartilage and bone. Eur Thyroid J. 2013;2(1):3-13.

34. Sun K, Luo J, Guo J, Yao X, Jing X, Guo F. The PI3K/AKT/mTOR signaling pathway in osteoarthritis: a narrative review. Osteoarthritis Cartilage. 2020; 28(4):400-9.

35. Sainio $A$, Järveläinen $H$. Extracellular matrix-cell interactions: focus on therapeutic applications. Cell Signal. 2020;66:109487.

36. Cheng BF, Lian JJ, Yang HJ, Wang L, Yu HH, Bi JJ, Gao YX, Chen SJ, Wang M, Feng ZW. Neural cell adhesion molecule regulates chondrocyte hypertrophy in chondrogenic differentiation and experimental osteoarthritis. Stem Cells Transl Med. 2020;9(2):273-83.

37. Mienaltowski MJ, Huang L, Bathke AC, Stromberg AJ, MacLeod JN. Transcriptional comparisons between equine articular repair tissue, neonatal cartilage, cultured chondrocytes and mesenchymal stromal cells. Brief Funct Genomics. 2010;9(3):238-50. 
38. Pei M, Luo J, Chen Q. Enhancing and maintaining chondrogenesis of synovial fibroblasts by cartilage extracellular matrix protein matrilins. Osteoarthritis Cartilage. 2008;16(9):1110-7.

39. Pace JM, Corrado M, Missero C, Byers PH. Identification, characterization and expression analysis of a new fibrillar collagen gene, COL27A1. Matrix Biol. 2003:22(1):3-14.

40. Kusafuka K, Hiraki Y, Shukunami C, Kayano T, Takemura T. Cartilage-specific matrix protein, chondromodulin-I (ChM-I), is a strong angio-inhibitor in endochondral ossification of human neonatal vertebral tissues in vivo: relationship with angiogenic factors in the cartilage. Acta Histochem. 2002;104(2):167-75.

41. Derfoul A, Perkins GL, Hall DJ, Tuan RS. Glucocorticoids promote chondrogenic differentiation of adult human mesenchymal stem cells by enhancing expression of cartilage extracellular matrix genes. Stem Cells. 2006;24(6):1487-95.

42. Ochi K, Derfoul A, Tuan RS. A predominantly articular cartilage-associated gene, SCRG1, is induced by glucocorticoid and stimulates chondrogenesis in vitro. Osteoarthritis Cartilage. 2006;14(1):30-8.

43. Lei $R$, Zhang $K$, Liu $K$, et al. Transferrin receptor facilitates TGF- $\beta$ and BMP signaling activation to control craniofacial morphogenesis. Cell Death Dis. 2016;7(6):e2282.

44. Zelzer E, Mamluk R, Ferrara N, Johnson RS, Schipani E, Olsen BR. VEGFA is necessary for chondrocyte survival during bone development. Development. 2004;131(9):2161-71.

45. Schultz M, Jin W, Waheed A, Moed BR, Sly W, Zhang Z. Expression profile of carbonic anhydrases in articular cartilage. Histochem Cell Biol. 2011;136(2): 145-51.

46. Steinbusch MMF, Caron MMJ, Surtel DAM, van den Akker GGH, van Dijk PJ Friedrich F, Zabel B, van Rhijn LW, Peffers MJ, Welting TJM. The antiviral protein viperin regulates chondrogenic differentiation via CXCL10 protein secretion. J Biol Chem. 2019:294(13):5121-36.

47. Courtial N, Smink JJ, Kuvardina ON, Leutz A, Göthert JR, Lausen J. Tal1 regulates osteoclast differentiation through suppression of the master regulator of cell fusion DC-STAMP. FASEB J. 2012;26(2):523-32.

48. Sato $\mathrm{T}$, Kudo $\mathrm{T}$, Ikehara $\mathrm{Y}$, et al. Chondroitin sulfate $\mathrm{N}$ acetylgalactosaminyltransferase 1 is necessary for normal endochondral ossification and aggrecan metabolism. J Biol Chem. 2011;286(7):5803-12.

49. Taylor SE, Lee J, Smeriglio P, et al. Identification of human juvenile chondrocyte-specific factors that stimulate stem cell growth. Tissue Eng Part A. 2016;22(7-8):645-53.

50. Hankenson KD, Hormuzdi SG, Meganck JA, Bornstein P. Mice with a disruption of the thrombospondin 3 gene differ in geometric and biomechanical properties of bone and have accelerated development of the femoral head. Mol Cell Biol. 2005;25(13):5599-606.

51. Unguryte A, Bernotiene E, Bagdonas E, Garberyte S, Porvaneckas N, Jorgensen C. Human articular chondrocytes with higher aldehyde dehydrogenase activity have stronger expression of COL2A1 and SOX9. Osteoarthritis Cartilage. 2016;24(5):873-82

52. Chien SY, Tsai CH, Liu SC, et al. Noggin inhibits IL-1 $\beta$ and BMP-2 expression, and attenuates cartilage degeneration and subchondral bone destruction in experimental osteoarthritis. Cells. 2020;9(4):927.

53. Chen JY, Tan X, Wang ZH, et al. The ribosome biogenesis protein Esf1 is essential for pharyngeal cartilage formation in zebrafish. FEBS J. 2018; 285(18):3464-84

54. Akagi R, Akatsu Y, Fisch KM, Alvarez-Garcia O, Teramura T, Muramatsu Y, Saito M, Sasho T, Su Al, Lotz MK. Dysregulated circadian rhythm pathway in human osteoarthritis: NR1D1 and BMAL1 suppression alters TGF- $\beta$ signaling in chondrocytes. Osteoarthritis Cartilage. 2017;25(6):943-51.

55. Asmar A, Barrett-Jolley R, Werner A, Kelly R Jr, Stacey M. Membrane channel gene expression in human costal and articular chondrocytes. Organogenesis. 2016;12(2):94-107.

56. Repudi SR, Patra M, Sen M. WISP3-IGF1 interaction regulates chondrocyte hypertrophy. J Cell Sci. 2013;126(Pt 7):1650-8.

57. Blazek AD, Nam J, Gupta R, Pradhan M, Perera P, Weisleder NL, Hewett TE, Chaudhari AM, Lee BS, Leblebicioglu B, Butterfield TA, Agarwal S. Exercisedriven metabolic pathways in healthy cartilage. Osteoarthritis Cartilage. 2016;24(7):1210-22.

58. Zhong Y, Yang J, Xu WW, Wang Y, Zheng CC, Li B, He QY. KCTD12 promotes tumorigenesis by facilitating CDC25B/CDK1/Aurora A-dependent G2/M transition. Oncogene. 2017;36(44):6177-89.

59. Zhu LJ, Pan Y, Chen XY, Hou PF. BUB1 promotes proliferation of liver cancer cells by activating SMAD2 phosphorylation. Oncol Lett. 2020;19(5):3506-12.
60. Yang J, Dong Z, Ren A, Fu G, Zhang K, Li C, Wang X, Cui H. Antibiotic tigecycline inhibits cell proliferation, migration and invasion via downregulating CCNE2 in pancreatic ductal adenocarcinoma. J Cell Mol Med. 2020;24(7):4245-60

61. Li P, Yang W, Shen B, Li H, Yan J. Lentivirus-mediated silencing of MPHOSPH8 inhibits MTC proliferation and enhances apoptosis. Oncol Lett. 2016;11(6):4117-22.

62. Schmidt F, Kunze M, Loock AC, Dobbelstein M. Screening analysis of ubiquitin ligases reveals G2E3 as a potential target for chemosensitizing cancer cells. Oncotarget. 2015;6(2):617-32.

63. Guo X, Williams JG, Schug TT, Li X. DYRK1A and DYRK3 promote cell survival through phosphorylation and activation of SIRT1. J Biol Chem. 2010;285(17): 13223-32.

64. Xie S, Qin J, Liu S, et al. Cep70 overexpression stimulates pancreatic cancer by inducing centrosome abnormality and microtubule disorganization. Sci Rep. 2016:6:21263.

65. He P, Zhang Z, Liao W, Xu D, Fu M, Kang Y. Screening of gene signatures for rheumatoid arthritis and osteoarthritis based on bioinformatics analysis. Mol Med Rep. 2016;14(2):1587-93.

66. Yammani RR. S100 proteins in cartilage: role in arthritis. Biochim Biophys Acta. 2012;1822(4):600-6.

67. Zhang C, Li T, Chiu KY, Wen C, Xu A, Yan CH. FABP4 as a biomarker for knee osteoarthritis. Biomark Med. 2018;12(2):107-18.

68. Loeser RF, Olex AL, McNulty MA, Carlson CS, Callahan M, Ferguson C, Fetrow JS. Disease progression and phasic changes in gene expression in a mouse model of osteoarthritis. PLoS One. 2013;8(1):e54633.

69. Haseeb A, Haqqi TM. Immunopathogenesis of osteoarthritis. Clin Immunol. 2013;146(3):185-96.

70. Gelse K, Ekici AB, Cipa F, Swoboda B, Carl HD, Olk A, Henning FF, Klinger P. Molecular differentiation between osteophytic and articular cartilage--clues for a transient and permanent chondrocyte phenotype. Osteoarthritis Cartilage. 2012;20(2):162-71.

71. Wei K, Korsunsky I, Marshall IL, W, Gao A, Watts GFM, Major T, Croft AP, Watts J, Blazar PE, Lange JK, Thornhill TS, Filer A, Raza K, Donlin LT, Siebel CW, Buckley CD, Raychaudhuri S, Brenner MB. Notch signalling drives synovial fibroblast identity and arthritis pathology. Nature. 2020;582(7811):259-264

72. van der Voort R, van Lieshout AW, Toonen LW, Sloetjes AW, van den Berg WB, Figdor CG, Radstake TR, Adema GJ. Elevated CXCL16 expression by synovial macrophages recruits memory T cells into rheumatoid joints. Arthritis Rheum. 2005;52(5):1381-91.

73. Maia M, de Vriese A, Janssens T, Moons M, van Landuyt K, Tavernier J, Lories RJ, Conway EM. CD248 and its cytoplasmic domain: a therapeutic target for arthritis. Arthritis Rheum. 2010;62(12):3595-606.

74. Luchetti MM, Piccinini G, Mantovani A, Peri G, Matteucci C, Pomponio G, Fratini M, Fraticelli P, Sambo P, Di Loreto C, Doni A, Introna M, Gabrieli A. Expression and production of the long pentraxin PTX3 in rheumatoid arthritis (RA). Clin Exp Immunol. 2000;119(1):196-202

75. Khanzadeh A, Habibagahi Z, Hosseini A, Amirghofran Z. Investigation of the human FCRL1, 2, and 4 gene expressions in patients with rheumatoid arthritis. Rheumatol Int. 2016:36(8):1149-56.

76. You S, Yoo SA, Choi S, Kim JY, Park SJ, Ji JD, Kim TH, Kim KJ, Cho CS, Hwang D. Kim WU. Identification of key regulators for the migration and invasion of rheumatoid synoviocytes through a systems approach. Proc Natl Acad Sci U S A. 2014;111(1):550-555.

77. Jiang H, Wang L, Pan J. Inhibition of pro-protein convertase subtilisin/kexin type 6 has a protective role against synovitis in a rat model of rheumatoid arthritis. Mol Med Rep. 2015;12(5):7681-6.

78. Gurol G, Ciftci IH, Harman H, Karakece E, Kamanli A, Tekeoglu I. Roles of claudin-5 and von Willebrand factor in patients with rheumatoid arthritis. Int J Clin Exp Pathol. 2015:8(2):1979-84.

79. Tamiya G, Shinya M, Imanishi T, Ikuta T, Makino S, Okamoto K, Furugaki K, Matsumoto T, Mano S, Ando S, Nozaki Y, Yukawa W, Nakashige R, Yamaguchi D, Ishibashi H, Yonekura M, Nakami Y, Takayama S, Endo T, Saruwatari T, Yagura M, Yoshikawa Y, Fujimoto K, Oka A, Chiku S, SEV L, Giphart M, Kulski JK, Fukazawa T, Hashimoto H, Kimura M, Hoshina Y, Suzuki Y, Hotta T, Mochida J, Minezaki T, Komai K, Shiozawa S, Taniguchi A, Yamanaka H, Kamatani N, Gojobori T, Bahram S, Inoko H. Whole genome association study of rheumatoid arthritis using 27039 microsatellites. Hum Mol Genet. 2005:14(16):2305-21.

80. Nguyen NT, Nakahama T, Nguyen CH, Tran TT, Le VS, Chu HH, Kishimoto T. Aryl hydrocarbon receptor antagonism and its role in rheumatoid arthritis. Exp Pharmacol. 2015;7:29-35. 
81. Castañeda-Delgado JE, Bastián-Hernandez Y, Macias-Segura N, SantiagoAlgarra D, Castillo-Ortiz JD, Alemán-Navarro AL, Martínez-Tejada P, EncisoMoreno L, Garcia-De Lira Y, Olguín-Calderón D, Trouw LA, Ramos-Remus C, Enciso-Moreno JA. Type I interferon gene response is increased in early and established rheumatoid arthritis and correlates with autoantibody production. Front Immunol. 2017;8:285.

82. Kurreeman FA, Daha NA, Chang M, Catanese JJ, Begovich AB, Huizinga TWJ, Toes REM. Association of IL2RA and IL2RB with rheumatoid arthritis: a replication study in a Dutch population. Ann Rheum Dis. 2009;68(11):1789-90.

83. Ramos MI, Teunissen MB, Helder B, Aarrass S, de Hair MJH, van Kuijk AW, Gerlag DM, Tak PP, Lebre MC. Reduced CLEC9A expression in synovial tissue of psoriatic arthritis patients after adalimumab therapy. Rheumatology (Oxford). 2016;55(9):1575-84.

84. Takano S, Uchida K, Miyagi M, Inoue G, Aikawa J, Iwabuchi K, Takaso M. Adrenomedullin regulates $\mathrm{IL}-1 \beta$ gene expression in $\mathrm{F} 4 / 80+$ macrophages during synovial inflammation. J Immunol Res. 2017;2017:9832430.

85. Tsolis KC, Bei ES, Papathanasiou I, Kostopoulou F, Gkretsi V, Kalantzaki K, Malizos K, Zervakis M, Tsezou A, Economou A. Comparative proteomic analysis of hypertrophic chondrocytes in osteoarthritis. Clin Proteomics. 2015;12(1):12

86. Zhou Y, Wang Z, Chen X, Zhang J, Yang L, Liu S, Liu Y. Identification of differentially expressed miRNAs and mRNAs in synovial of osteoarthritis via RNA-sequencing. BMC Med Genet. 2020;21(1):46.

87. Aki T, Hashimoto K, Ogasawara M, Itoi E. A whole-genome transcriptome analysis of articular chondrocytes in secondary osteoarthritis of the hip. PLoS One. 2018:13(6):e0199734.

88. Sebastian A, Murugesh DK, Mendez ME, Hum NR, Rios-Arce ND, McCool JL, Christiansen BA, Loots GG. Global gene expression analysis identifies agerelated differences in knee joint transcriptome during the development of post-traumatic osteoarthritis in mice. Int J Mol Sci. 2020;21(1):364.

89. Chang ZK, Meng FG, Zhang ZQ, Mao GP, Huang ZY, Liao WM, He AS. MicroRNA-193b-3p regulates matrix metalloproteinase 19 expression in interleukin-1 $\beta$-induced human chondrocytes. J Cell Biochem. 2018;119(6): 4775-82.

90. Troeberg L, Nagase H. Proteases involved in cartilage matrix degradation in osteoarthritis. Biochim Biophys Acta. 2012;1824(1):133-45.

91. Hu PF, Tang JL, Chen WP, Bao JP, Wu LD. Increased apelin serum levels and expression in human chondrocytes in osteoarthritic patients. Int Orthop. 2011:35(9):1421-6.

92. Gardiner MD, Vincent TL, Driscoll C, Burleigh A, Bou-Gharios G, Saklatvala J, Nagase H, Chanalaris A. Transcriptional analysis of micro-dissected articular cartilage in post-traumatic murine osteoarthritis. Osteoarthritis Cartilage. 2015;23(4):616-28.

93. Burleigh A, Chanalaris A, Gardiner MD, Driscoll C, Boruc O, Saklatvala 」, Vincent TL. Joint immobilization prevents murine osteoarthritis and reveals the highly mechanosensitive nature of protease expression in vivo. Arthritis Rheum. 2012;64(7):2278-88.

94. Lu QY, Han QH, Li X, Li ZC, Pan YT, Liu L, Fu QG. Analysis of differentially expressed genes between rheumatoid arthritis and osteoarthritis based on the gene co-expression network. Mol Med Rep. 2014;10(1):119-24.

\section{Publisher's Note}

Springer Nature remains neutral with regard to jurisdictional claims in published maps and institutional affiliations.

Ready to submit your research? Choose BMC and benefit from:
- fast, convenient online submission
- thorough peer review by experienced researchers in your field
- rapid publication on acceptance
- support for research data, including large and complex data types
- gold Open Access which fosters wider collaboration and increased citations
- maximum visibility for your research: over 100M website views per year
At BMC, research is always in progress.
Learn more biomedcentral.com/submissions

